Case Study

\title{
INTERLEUKIN-17INHIBITION WITH SECUKINUMAB IMPROVES SUDOMOTOR DYSFUNCTION IN PSORIATIC ARTHRITIS
}

\author{
ASHIT SYNGLE ${ }^{1,2}$, INDERJEET VERMA ${ }^{3}$, SUDEEP KAUR ${ }^{4}$, TANYA SYNGLE 5 \\ ${ }^{1}$ Cardio-Rheuma and Healing Touch City Clinic, Chandigarh, ${ }^{2}$ Fortis Multi Specialty Hospital, Mohali, India, ${ }^{3}$ Maharishi Markandeshwar \\ College of Pharmacy, M M University, Ambala, Haryana, India, ${ }^{4}$ Department of Kayachikitsa, Postgraduate School of Ayurveda and \\ Research Mandi Gobindgarh, Punjab, India, ${ }^{5}$ Healing Touch Foundation, Chandigarh, India \\ Email: indupup@gmail.com
}

Received: 19 Sep 2017 Revised and Accepted: 11 Jan 2018

\begin{abstract}
Psoriatic arthritis (PsA) is a relapsing inflammatory disease, most commonly a seronegative oligoarthritis found in patients with psoriasis, characterized by the absence of rheumatoid factor in serum, with differentiating features of distal joint involvement and in extreme cases of arthritis mutilans (which is a destructive form of PsA). Cardiovascular autonomic and peripheral sympathetic neuropathy occurs in PsA. However, there is no specific treatment recommendation for autonomic neuropathy (AN) in psoriatic diseases. Secukinumab, a recently approved therapeutic advancement for psoriasis and psoriatic arthritis, is an immunoglobulin G (IgG) $1 \mathrm{k}$ fully monoclonal antibody that selectively inhibits the effector function of interleukin (IL)-17A. Its effect on sudomotor dysfunction in PsA has not yet been reported. This is the first reported observation of improvement in peripheral sympathetic autonomic neuropathy with secukinumab in PsA. We report a case of a 52-year-old male with PsA on methotrexate $15 \mathrm{mg} /$ week with severe disease activity treated with the addition of subcutaneous secukinumab $150 \mathrm{mg}$ once a week for $5 \mathrm{w}$ followed by once a month dose. We found significant improvement in sudomotor dysfunction after 4 and $8 \mathrm{w}$ of treatment.
\end{abstract}

Keywords: Psoriatic arthritis, Sudomotor dysfunction, Secukinumab, Autonomic neuropathy, Psoriasis

(C) 2018 The Authors. Published by Innovare Academic Sciences Pvt Ltd. This is an open access article under the CC BY license (http://creativecommons.org/licenses/by/4.0/] DOI: http://dx.doi.org/10.22159/ijpps.2018v10i3.22660

\section{INTRODUCTION}

A skin and joint disease with multifactorial etiology, psoriasis affects $1-2 \%$ of the general population [1]. Typically PsA involves joints of the axial skeleton with an asymmetrical pattern. The spectrum of symptoms includes inflammatory changes in attachments of articular capsules, tendons, and ligaments to the bone surface [1]. The disease can have a diverse clinical course but usually, manifests as oligoarthritis [1]. Peripheral sympathetic autonomic dysfunction in psoriatic arthritis is known [2]. Secukinumab is an IgG1k fully monoclonal antibody selectively targeting interleukin-17A. IL-17A neutralized by secukinumab rapidly inhibits downstream inflammatory cytokine and chemokine networks and thus may be useful for the treatments of several immune-mediated diseases [3]. Interleukin 17A and its receptor are expressed in synovial tissues and as such the interleukin 17 pathway is proposed to contribute to the pathogenesis of psoriatic arthritis [4]. Interleukin 17A can mediate a variety of effector biological functions that can result in joint and enthesial inflammation, damage, and tissue remodeling [4] Secukinumab with an alternative form of action to current treatments is useful as a biologic DMARD in PsA [4]. However, its effect on sudomotor dysfunction in PsA has not yet been reported. We here report the impact of treatment with this novel drug on sudomotor function in a case of PsA.

\section{CASE REPORT}

A 52-year-old gentleman with a 25 y history of PsA being treated with oral methotrexate $15 \mathrm{mg} /$ week since 15 y reported with increased joint pains and swelling for the last $9 \mathrm{mo}$. In addition to PsA, the patient had light-headedness and disturbed bowel movements suggestive of autonomic dysfunction. He is a teetotaler and a non-smoker. He is normotensive and non-diabetic and does not have thyroid dysfunction. He had an elevated erythrocyte sedimentation rate (ESR) of $73 \mathrm{~mm} / 1 \mathrm{st} \mathrm{hr}$ and high C-reactive protein (CRP) of $25 \mathrm{mg} / \mathrm{dl}$ and DAS-28 (Disease Activity Score in 28 joints) score was 6.3 (table 1). Radiographs are depicted in fig. 1. Symptoms of ANS were measured by asking a number of questions according to an easily administered instrument, known as a survey of autonomic symptoms [5].

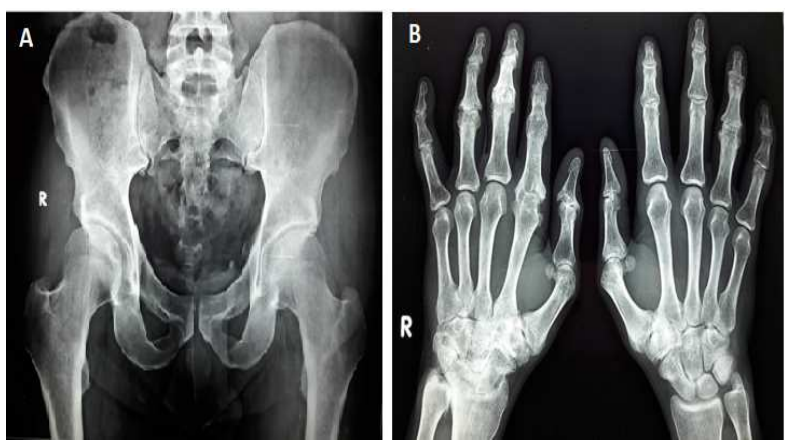

Fig. 1A: Radiograph of sacroiliac joints, subchondral sclerotic changes are seen in bilateral sacroiliac joints with preserved joint space (Grade II Sacroilitis), fig. 1B. radiographs of hand joints. Reduced bone density changes are seen in bilateral hands. Extensive Erosive Arthritis with loss of Joint space with Subchondral Bone Destruction and Sclerotic changes are seen in right 3rd PIP and DIP joints. Ankylosis changes are seen at right 2nd metacarpophalangeal, PIP and DIP joints. Similar ankylosis changes also seen at left 4th PIP Joint. Joint Space narrowing with subchondral sclerosis is seen at right $1^{\text {st }}$ interphalangeal joint, 4th PIP joint with osteophytes formation. Similar changes also

were seen at left $2^{\text {nd }}, 3^{\text {rd }}$ and $4^{\text {th }}$ PIP and DIP joints. Erosive arthritic changes also were seen at $B / l$ trapeziometacarpal and $2^{\text {nd }}$ carpometacarpal joints with subchondral sclerotic changes joint space narrowing with sclerotic changes is seen at right Intercarpal joints, radioscaphoid joint and distal radioulnar joint

The peripheral sympathetic autonomic function was measured by non-invasive device Sudoscan (Sudoscan Impeto Medical Device, EZS 01750010193 Paris, France) [6]. Sudoscan is a FDA approved device designed to perform the precise evaluation of sweat gland function based on sweat chloride concentrations through reverse iontophoresis and chronoamperometry. Through reverse iontophoresis, the device generates a voltage to the cathode and a 
current (intensity of around $0.2 \mathrm{~mA}$ ) between the anode and cathode proportional to chloride concentration. At low voltages $(60 \mu \mathrm{S}=$ no dysfunction; 60-40 $\mu \mathrm{S}=$ moderate dysfunction [6]. Sudomotor function test was performed before the initiation of treatment and after each treatment interval. Sudomotor function test showed marked abnormalities of peripheral sympathetic function (table 1 and fig. 2). No other cause of neuropathy was found from the detailed clinical history, physical examination and biochemical screening (serum vitamin B12 deficiency, Thyroid Function Tests (T3, T4, TSH), fasting blood sugar, HbA1c, HbsAg, Anti-HCV, HIV).

Table 1: Results of sudomotor function and clinical tests

\begin{tabular}{lllll}
\hline & Time Interval & & \\
\hline Variables & $\mathbf{0 ~ w}$ & $\mathbf{4} \mathbf{w}$ & $\mathbf{8 ~ w}$ & Normal value \\
\hline Sudoscan $(\mu \mathrm{s})$ & 43 & 56 & 72 & $>60$ \\
ESR $(\mathrm{mm} / 1 \mathrm{~h})$ & 73 & 25 & 10 & $0-10$ \\
CRP $(\mathrm{mg} / \mathrm{l})$ & 25 & 6 & 5.10 & $<6$ \\
DAS-28 & 6.3 & 4.73 & 2.42 & $<2.5$ \\
HAQ-DI & 2 & 1 & 0.1 & -- \\
\hline
\end{tabular}

ESR; erythrocyte sedimentation rate, CRP; C-reactive protein, DAS-28; disease activity score of 28 joints, HAQ-DI; health assessment questionnaire.

Secukinumab $150 \mathrm{mg}$ subcutaneous was added to MTX $15 \mathrm{mg} /$ week on day $0,7,14,21$ and day 28 as a loading dose followed by maintenance dose of $150 \mathrm{mg}$ once a month. After the first dose of Secukinumab $150 \mathrm{mg}$ subcutaneous, there was a rapid improvement in autonomic symptoms and sudomotor dysfunction (fig. 2) and normal values were achieved after $8 \mathrm{w}$ of treatment. ESR, CRP and DAS-28 scores were reduced (table 1) and autonomic symptoms disappeared after $8 \mathrm{w}$ of secukinumab administration. After 4 and 8 $\mathrm{w}$ treatment with secukinumab, there was a great improvement in the quality of life assessed by HAQ-DI (table 1).

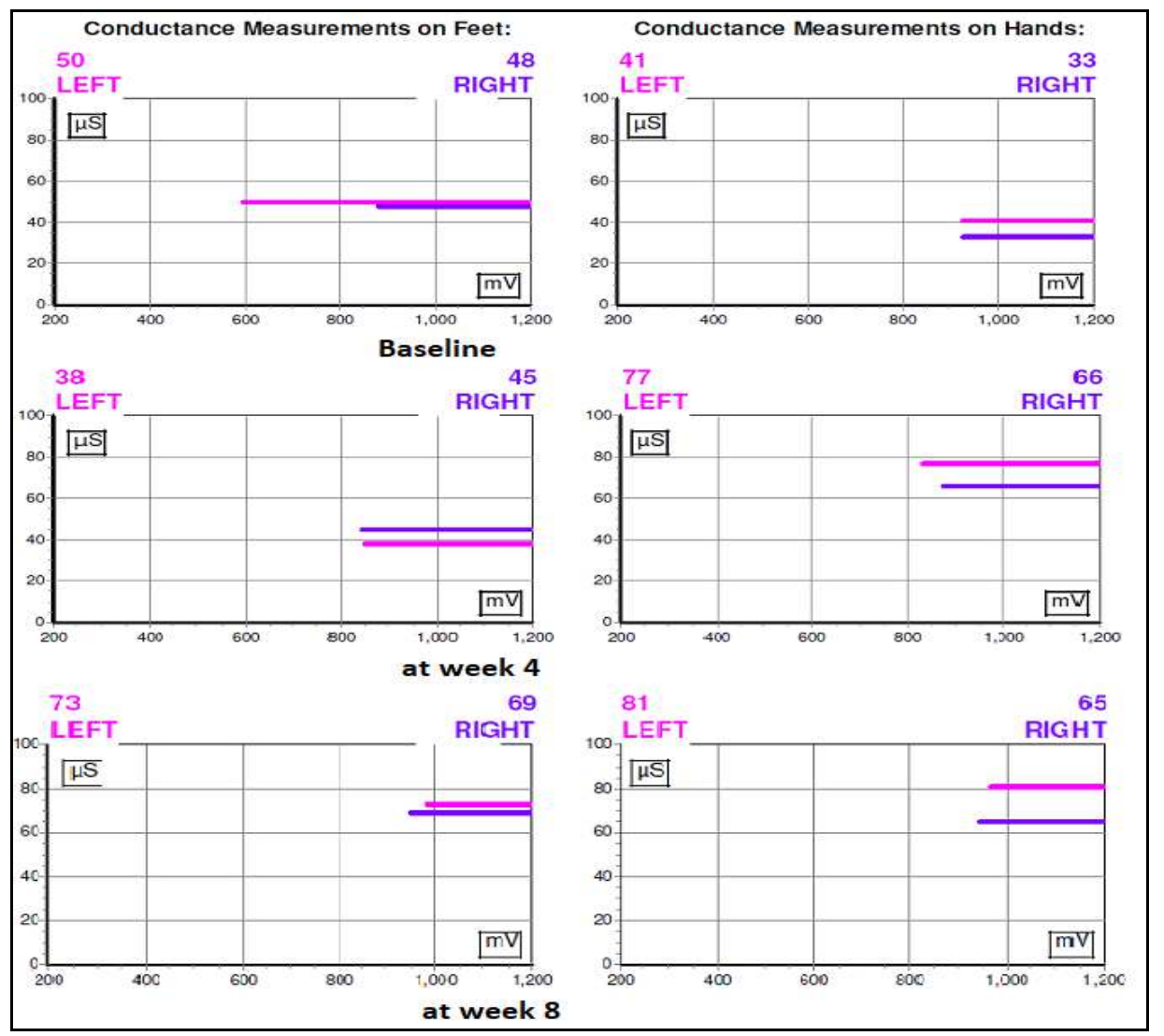

Fig. 2: Sudomotor function at baseline and after 4 and $8 \mathrm{w}$ of treatment with secukinumab

\section{DISCUSSION}

We have shown in this case with active psoriatic arthritis a significant improvement in inflammatory disease activity and sudomotor dysfunction along with resolution of autonomic symptoms after treatment with secukinumab. Syngle et al. in 2013 first described the involvement of autonomic dysfunction in PsA patients with $37.5 \%$ having moderate sudomotor dysfunction [2]. Haliguret al. have reported sympathetic nervous system dysfunction in psoriasis but did not investigate sudomotor dysfunction [7].
The pathogenesis of peripheral sympathetic autonomic dysfunction and its treatment in PsA is still unknown. Sudomotor dysfunction reflects small fiber neuropathy, cardiovascular autonomic neuropathy and peripheral sympathetic autonomic neuropathy [6]. The early diagnosis and appropriate treatment of autonomic neuropathy are important because of higher risk of CV morbidity and mortality [8]. Cardiovascular autonomic neuropathy is a significant risk predictor for sudden cardiac death in autoimmune rheumatic diseases [9].

In the present case study, the index patient with active PsA had sympathetic dysfunction along with some autonomic symptoms. 
Secukinumab, when added to methotrexate significantly, reduced the high disease activity, inflammation, autonomic symptoms and abnormal sudomotor dysfunction. Though symptoms of autonomic dysfunction may be absent or occur with varying frequency and intensity, sympathetic nervous system dysfunction can be detected non-invasively and is important to prevent severe consequences including myocardial infarction, arrhythmias and sudden cardiac death.

The role of proinflammatory cytokines, including TNF- $\alpha$, IL-1, IL-6, IL8, IL-10, IL-12, IL-17 and IL-23, has been demonstrated within the joint in psoriatic arthritis and relationship between cytokine levels and clinical arthritis severity demonstrated [10]. The proinflammatory cytokine Interleukin 17 (IL-17) has recently emerged as a key proinflammatory cytokine that orchestrates immune responses during infection, acute inflammation, allergy and autoimmune disease. It is secreted by immune cells such as Th17 cells, and its receptors are ubiquitously expressed. Th-17 cells and innate IL-17 producers have been shown to be important players of IL-17-induced effects in the joint [11]. IL-17, being a proinflammatory cytokine, in turn, acts on synovium, macrophages, dendritic cells, endothelial cells, chemokines, entheseal cells and osteoclasts [11].

IL-17 effects in PsA are mediated through IL-1, IL-6, IL-8, TNF- $\alpha$, MMP-3, receptor activator of NFKB [12]. Blockage of IL-17 receptor (IL-17RA) with anti-IL-17 RA antibody (secukinumab) inhibited the production of IL-6, IL-8 and matrix metalloproteinase-3 (MMP-3) [13]. Overproduction of IL-17 can affect different parts of the body in PsA resulting in significant disability and poor quality of life [13]. Through the induction of other cytokines like IL-6, TNF- $\alpha$ and nitric oxide, IL-17 may also result in complications like accelerated atherosclerosis and autonomic dysfunction [12].

Both in ankylosing spondylitis and PsA, the cytokine-mediated inflammatory process may contribute to the autonomic abnormalities $[2,14]$. On the other hand, there is also evidence for the contribution of the nervous system to inflammation $(2,14,15]$. Thus it is possible that the sudomotor dysfunction associated with PsA is likely to be immune-mediated and driven by the inflammatory state that characterizes the disease.

Hence treatment with IL-17A monoclonal antibody, secukinumab, through its IL-17R blocking action with resultant immunemodulatory and anti-inflammatory effect can have beneficial effects on the sudomotor dysfunction of PsA.

\section{CONCLUSION}

To the best of our knowledge, this is the first case study to report the therapeutic impact of secukinumab on sudomotor dysfunction in active PsA. Although we were unable to investigate the mechanism of improvement of sympathetic dysfunction, our findings indicate that IL-17A blockade with secukinumab does have the immunemodulatory and anti-inflammatory potential as well as appears to exert a beneficial effect on sudomotor dysfunction in PsA. This case report assumes significance given the fact that autonomic dysfunction has been linked to a reduced quality of life and serious and potentially life-threatening cardiovascular complications.

\section{ACKNOWLEDGEMENT}

We wish to acknowledge the radiological expertise of Dr. Aman Deepak, MD, Radiology.

\section{AUTHORS CONTRIBUTIONS}

ASHIT SYNGLE: Patient assessment and case study designing
INDERJEET VERMA: Manuscript writing and sudomotor function testing

SUDEEP KAUR: Patient assessment

TANYA SYNGLE: Manuscript writing

\section{CONFLICT OF INTERESTS}

Declared none

\section{REFERENCES}

1. Khopkar U, Pandey S. Skin manifestations of rheumatic diseases. In: Syngle A, Deodhar SD. editors. Rheumatology principles and practice. $1^{\text {st }}$ ed. Jaypee Brothers Medical Publisher; 2010. p. 413.

2. Syngle A, Verma I, Garg N, Krishan P. Autonomic dysfunction in psoriatic arthritis. Clin Rheumatol 2013;32:1059-64.

3. Mclnnes IB, Mease PJ, Kirkham B, Kavanaugh A, Ritchlin CT, Rahman $\mathrm{P}$, et al. Secukinumab, a human anti-interleukin-17A monoclonal antibody, in patients with psoriatic arthritis (FUTURE 2): a randomised, double-blind, placebo-controlled, phase 3 trial. Lancet 2015;386:1137-46.

4. FitzGerald O, Winchester R. Emerging evidence for the critical involvement of interleukin-17 pathway in both psoriasisl and psoriatic arthritis. Arthritis Rheumatol 2014;66:1077-80.

5. Zilliox L, Peltier AC, Wren PA, Anderson A, Smith AG, Singleton $\mathrm{JR}$, et al. Assessing autonomic dysfunction in early diabetic neuropathy: the survey of autonomic symptoms. Neurology 2011;76:1099-105.

6. Mayaudon H, Miloche PO, Bauduceau B. A new method for assessing sudomotor function: relevance in type 2 diabetes. Diabetes Metab 2010;36:450-4.

7. Halıgur BD, Cicek D, Bulut S, Berilgen MS. The investigation of autonomic functions in patients with psoriasis. Int J Dermatol 2012;51:557-63.

8. Boulton AJ, Freeman R, Vinik AI. Diabetic neuropathies: a statement by the American diabetes association. Diabetes Care 2005;28:956-62.

9. Milovanovic B, Stojanovic L, Nebojsa Milicevic N, Vasic K, Bjelakovic B, Krotin M. Cardiac autonomic dysfunction in patients with systemic lupus, rheumatoid arthritis and sudden death risk. Srp Arh Celok Lek 2010;138:26-32.

10. Szodoray P, Alex P, Chappell-Woodward CM, Madland TM, Knowlton N, Dozmorov I, et al. Circulating cytokines in Norwegian patients with psoriatic arthritis determined by a multiplex cytokine array system. Rheumatology 2007;46:417-25.

11. Truchetet ME, Mossalayi MD, Boniface K. IL-17 in the rheumatologist's line of sight. Biomed Res Int 2013. http://dx.doi.org/10.1155/2013/295132

12. Kellner H. Targeting interleukin 17 in patients with active rheumatoid arthritis: rationale and clinical potential. Adv Musculoskelet Dis 2013;5:141-52.

13. Raychaudhuri SP, Raychaudhuri SK. Mechanistic rationales for targeting interleukin-17A in spondyloarthritis. Arthritis Res Ther 2017; 19:51.

14. Toussirot E, Bouhaddi MB, Poncet JC, Cappelle S, Henriet MT, Wendling $\mathrm{D}$, et al. Abnormal autonomic cardiovascular control in ankylosing spondylitis. Ann Rheum Dis 1999;58:481-7.

15. Levine JD, Goetzl EJ, Basbaum AI. The contribution of the nervous system to the pathophysiology of rheumatoid arthritis and other polyarthritides. Rheum Dis Clin North Am 1987;13:369-83. 